\title{
Development and implementation of an inpatient multidisciplinary pain management program for patients with intractable chronic musculoskeletal pain in Japan: preliminary report
}

This article was published in the following Dove Press journal:

Journal of Pain Research

\author{
Naoto Takahashi, ${ }^{1,2}$ \\ Satoshi Kasahara ${ }^{1,2}$ \\ Shoji Yabuki ${ }^{1,2}$ \\ 'Department of Pain Medicine, \\ Fukushima Medical University \\ School of Medicine, Fukushima, ${ }^{2}$ Pain \\ Management Center, Hoshi General \\ Hospital, Koriyama, Japan
}

\begin{abstract}
Introduction: Multidisciplinary pain management is a useful method to treat chronic musculoskeletal pain. Few facilities in Japan administer a multidisciplinary pain management program, especially an inpatient program. Therefore, we implemented a multidisciplinary pain management program in our hospital based on biopsychosocial factors guided by the recommendations of the International Association for the Study of Pain. The purpose of this study is to describe our inpatient pain management program for Japanese patients, which uses the biopsychosocial method of pain self-management.
\end{abstract}

Materials and methods: Fourteen patients with intractable chronic musculoskeletal pain, who were implemented a multidisciplinary pain management program in our hospital, were studied using the evaluation of the pain and associated factors and physical function.

Results: Significant improvement in outcomes were seen in the brief pain inventory, the pain catastrophizing scale (rumination, magnification, and helplessness), the pain disability assessment scale, the hospital anxiety and depression scale (anxiety and depression), the pain self-efficacy questionnaire, the EuroQol five dimensions questionnaire, and muscle endurance and physical fitness. We found no statistically significant differences in static flexibility or walking ability. Conclusion: We developed an inpatient chronic pain management program for Japanese patients. Our results suggest that our program improves chronic musculoskeletal pain coping mechanisms, and that the program can improve patients' quality of life and some physical function. This inpatient pain management program is being expanded to better help intractable chronic musculoskeletal pain patients.

Keywords: chronic musculoskeletal pain, multidisciplinary pain management, biopsychosocial model, inpatient pain management program

\section{Introduction}

It is sometimes difficult to treat chronic musculoskeletal pain because the related symptoms vary and the pathophysiology is complex. The International Association for the Study of Pain (IASP) defines pain as "An unpleasant sensory and emotional experience associated with actual or potential tissue damage, or described in terms of such damage". ${ }^{1}$ Chronic pain states develop during tissue recovery following various injuries and may persist for long periods after tissue recovery. Because of its various manifestations, chronic pain may be difficult to treat successfully. Patient management using a multidisciplinary pain approach is a useful treatment method for chronic musculoskeletal pain, as has been demonstrated in the USA since 1960. A
Correspondence: Naoto Takahashi Department of Pain Medicine, Fukushima Medical University School of Medicine, I Hikarigaoka, Fukushima City, Fukushima 9601295 , Japan

Tel +8I 245471964

Fax +8I 245471966

Email naotot21।@aol.com 
biopsychosocial model ${ }^{2,3}$ of well-being is a very important concept in multidisciplinary pain management. This is a general model or approach stating that biological, psychological, and social factors play a significant role in human functioning in disease or illness. Multidisciplinary pain treatment requires special facilities; however, few facilities in Japan are able to provide a multidisciplinary pain approach, especially an inpatient multidisciplinary pain management program, because of the medical administration needs and the Japanese insurance system. We implemented an inpatient multidisciplinary pain management program in our hospital based on biopsychosocial models guided by the recommendations. $^{3-8}$ The purpose of this study is to describe our inpatient pain management program for Japanese patients, which uses the biopsychosocial method of pain self-management, and to show the preliminary results.

\section{Materials and methods Multidisciplinary pain management program}

The pain management center discussed in this study was implemented in the Hoshi General Hospital, technically supported by the Department of Pain Medicine, Fukushima Medical University School of Medicine, in April 2015 with a team of orthopedic surgeons, psychiatrists, nurses, physical therapists, clinical psychologists, pharmacists, and nutritionists. Our 3-week inpatient multidisciplinary pain management program is indicated for patients who have difficulty working or attending school because of intractable chronic musculoskeletal pain, and/or those who are confined to home but wish to return to work or school. The program consists of the following: 1) exercise therapy: physical fitness and individual training by physical therapists, which consisted of aerobic exercise (walking and/or underwater exercise), and strengthening and stretching of trunk muscle, leg muscle, and hip joint muscle, among other things. For strengthening, a sit-up exercise was used for the trunk flexor muscles and an extension exercise for the trunk extensor muscles, 6-7 hours a week, total 20 hours; 2) psychotherapy and cognitive behavioral therapy: assertiveness (60-120 minutes, total 3 times), relaxation training (60-120 minutes, total 2 times), and role playing to increase healthy behaviors and decrease pain behavior (60-120 minutes, total 2 times), led by psychologists; and 3) patient education by each specialist, which consisted of the lectures by orthopedic surgeon on pain mechanism, exercise and pacing by physical therapist, assertiveness and relaxation training by psychologist, side effects of drugs by pharmacist, and daily life habit associated with nutrition by nutritionists; each 30-60 minutes, total 20 times. The objectives of the program were for the patients to return to a functional daily life habit and to receive education in coping methods for intractable chronic musculoskeletal pain and guidance for a continuous exercise program. Finally, participation in some lectures and psychotherapy programs includes not only patients but also family members or significant others. ${ }^{8}$

\section{Role of each of the 7 specialists}

1. Orthopedic surgeons:

(a) To evaluate physical, neurological, and imaging findings, including radiographs/radiography, computed tomography, and magnetic resonance imaging, and to diagnose the presence of any specific musculoskeletal disorders.

(b) To treat with conservative therapy, including injectable therapy, pharmacotherapy, and cognitive behavioral therapy, if needed.

(c) To provide fundamental knowledge associated with chronic musculoskeletal pain to both patients and their family members or significant others.

(d) To confirm patients' changes in symptoms and levels of progress in the program, during morning and/or evening patient rounds.

2. Psychiatrists:

(a) To diagnose patients' psychological disorders associated with chronic musculoskeletal pain, including psychiatric disorders, pervasive developmental disorder, attention deficit hyperactivity disorder (ADHD), or personality disorder.

(b) To treat with conservative therapy, including pharmacotherapy and cognitive behavioral therapy, if needed.

3. Nurses:

(a) To observe inpatients' behaviors and support patients during hospitalization.

(b) To confer with patients regarding their anxiety and problems associated with chronic musculoskeletal pain, and to act as liaison between specialists.

4. Physical therapists:

(a) To evaluate the changes of physical function.

(b) To educate patients about exercise and stretching.

(c) To guide during strength training, with a focus on the trunk muscles and/or leg muscles to improve blood flow and muscle tone in the lumbar region.

(d) To help patients perform aerobic exercise, including walking and underwater exercise.

(e) To guide during voluntary training, including stretching, walking, and other exercises. 
(f) To educate about the importance of pacing during activity and working within each patient's limits of activity.

5. Clinical psychologists:

(a) To analyze patients' self-expression type: aggressive, defensive, or assertive.

(b) To guide self-expression to increase healthy behaviors using role playing for both patients and their family members.

(c) To explain the gate control theory associated with pain. ${ }^{8,9}$

(d) To educate about abdominal breathing and progressive muscle relaxation.

(e) To educate about the importance of pacing during activity and working within each patient's limits of activity.

6. Pharmacists:

(a) To explain the half-life of medications to prevent overdose, and to provide guidance about excess intake and its effects on internal medicine.

(b) To discuss the correct way to take the analgesic drugs orally based on the medical doctor's instructions.

(c) To educate patients about the different analgesic drugs and the side effects of opioids.

(d) To educate patients about endogenous opioids, and that oral analgesic drugs may not always be necessary.

7. Nutritionists:

(a) To analyze the average number of consumed calories based on photographs of what patients ate, including both staple foods and between-meal snacks for 3 days before hospitalization.

(b) To provide a nutrition plan after calculating calories spent during exercise, which is discussed during the treating program in collaboration with the physical therapists.

(c) To educate about lifestyle and nutritional support for both patients and their family members.

\section{Patients}

We evaluated 14 patients with intractable chronic musculoskeletal pain undergoing our inpatient multidisciplinary pain management program.

\section{Evaluations of pain and associated factors}

We evaluated inpatients with chronic musculoskeletal pain using 1) a brief pain inventory (BPI $)^{10}$ to assess pain severity; 2) a) an evaluation of the degree of rumination, magnification, and helplessness on a pain catastrophizing scale (PCS), ${ }^{11} \mathrm{~b}$ ) pain disability assessment scale (PDAS), ${ }^{12}$ c) anxiety and depression assessment using the hospital anxiety and depression scale (HADS) ${ }^{13}$ and d) a pain self-efficacy questionnaire
(PSEQ) $)^{14}$ to assess the psychosocial factors; and 3 ) the EuroQol five dimensions (EQ-5D) questionnaire ${ }^{15}$ to evaluate the quality of life (QOL). Physical function was also evaluated as follows: patients' degree of flexibility, muscle endurance evaluated using a 2-step test for walking ability, and 6 minutes of walking to assess physical fitness.

\section{Statistical analysis}

The paired $t$-test was used for statistical analyses. A $p$-value of $<0.05$ was considered statistically significant. Statistical analyses were performed using StatView 5.0 statistical software (SAS Institute, Cary, NC, USA).

\section{Ethics approval and consent to participate}

This study was approved by the ethics committees of the participating institutions of Fukushima Medical University (Reference number: 2429) and Hoshi General Hospital (Reference number: 27-3). All participants gave written informed consent for this study.

\section{Results}

Patients' clinical characteristics, chief complaints, structural disorders, and psychiatric diagnoses are shown in Table 1. Fourteen patients, who received our 3-week inpatient multidisciplinary pain management program from April 2015 to March 2017, were included. Comparing results before and after the program, the following significant improvement in outcomes were seen for 1) BPI; 2) rumination, magnification, helplessness and total on the PCS; 3) PDAS; 4) anxiety and depression score on the HADS; 5) PSEQ; 6) EQ-5D; 7) 30-second sit to stand test; and 8) 6-minute walking test (Figures 1 and 2, Tables 2 and 3). We found no statistically significant differences in the following scales: 1) static flexibility test and 2) two-step test (Figure 2 and Table 3).

\section{A representative case report}

Case 1: A 41-year-old man presented with a complaint of severe low back pain for 2 years. He had a history of depression, but no underlying diseases such as diabetes mellitus, renal failure, hypertension, or thyroid disease. He was diagnosed with lumbar disc herniation by a previous orthopedic surgeon at a private clinic and was treated with conservative therapy, including medication and physical therapy. However, he did not improve, and because he complained of general malaise later, a referral to a psychiatrist was recommended. He underwent treatment for depression, but his chief complaint of low back pain did not improve. He provided written informed consent to have the case details published. 
Table I Characteristics of 14 cases

\begin{tabular}{|c|c|c|c|}
\hline Case & Chief complaint & Structural disorder & Psychiatric diagnosis \\
\hline I. 4I-year-old man & Low back pain & None found & $\begin{array}{l}\text { Pervasive developmental disorder, attention deficit } \\
\text { hyperactivity disorder, somatoform disorders }\end{array}$ \\
\hline 2. 53-year-old woman & $\begin{array}{l}\text { Posterior cervical pain, bilateral } \\
\text { omalgia, low back pain }\end{array}$ & None found & $\begin{array}{l}\text { Dependency personality disorder, somatoform } \\
\text { disorders }\end{array}$ \\
\hline 3. 69-year-old woman & $\begin{array}{l}\text { Posterior cervical pain, bilateral } \\
\text { omalgia, low back pain }\end{array}$ & Spondylosis & $\begin{array}{l}\text { Compulsive personality disorder, somatoform } \\
\text { disorders }\end{array}$ \\
\hline 4. 55-year-old woman & $\begin{array}{l}\text { Posterior cervical pain, bilateral } \\
\text { upper extremity numbness }\end{array}$ & $\begin{array}{l}\text { Ossification of posterior } \\
\text { longitudinal ligament } \\
\text { (after surgery) }\end{array}$ & Narcissism personality disorder \\
\hline 5. 20-year-old man & Low back pain & None found & $\begin{array}{l}\text { Pervasive developmental disorder, attention deficit } \\
\text { hyperactivity disorder, somatoform disorders }\end{array}$ \\
\hline 6. 56-year-old woman & $\begin{array}{l}\text { Posterior cervical pain, bilateral } \\
\text { omalgia, low back pain, bilateral } \\
\text { gonalgia }\end{array}$ & $\begin{array}{l}\text { Spondylosis, knee } \\
\text { osteoarthritis }\end{array}$ & $\begin{array}{l}\text { Attention deficit hyperactivity disorder, dependency } \\
\text { personality disorder, somatoform disorders }\end{array}$ \\
\hline 7. 31-year-old woman & $\begin{array}{l}\text { Posterior cervical pain, bilateral } \\
\text { omalgia, low back pain }\end{array}$ & None found & None diagnosed \\
\hline 8. 47-year-old woman & Low back pain & None found & $\begin{array}{l}\text { Attention deficit hyperactivity disorder, histrionic } \\
\text { personality disorder, somatoform disorders }\end{array}$ \\
\hline 9. 56-year-old woman & Low back pain, left leg pain & None found & None diagnosed \\
\hline 10. 5I-year-old man & Low back pain & None found & $\begin{array}{l}\text { Pervasive developmental disorder, attention deficit } \\
\text { hyperactivity disorder, somatoform disorders }\end{array}$ \\
\hline II. 55-year-old man & $\begin{array}{l}\text { Posterior cervical pain, bilateral } \\
\text { omalgia, back pain, bilateral arm pain, } \\
\text { low back pain, bilateral leg pain }\end{array}$ & None found & $\begin{array}{l}\text { Pervasive developmental disorder, autism spectrum } \\
\text { disorder, attention deficit hyperactivity disorder, } \\
\text { somatoform disorders }\end{array}$ \\
\hline 12. 58-year-old woman & $\begin{array}{l}\text { Posterior cervical pain, bilateral } \\
\text { omalgia, low back pain, right coxalgia, } \\
\text { bilateral gonalgia, bilateral leg pain }\end{array}$ & $\begin{array}{l}\text { Right hip osteoarthritis, } \\
4^{\text {th }} \text { lumbar degenerative } \\
\text { spondylolisthesis }\end{array}$ & $\begin{array}{l}\text { Pervasive developmental disorder, attention deficit } \\
\text { hyperactivity disorder, somatoform disorders }\end{array}$ \\
\hline 13. 75-year-old woman & Low back pain, bilateral leg pain & Spondylosis & None diagnosed \\
\hline 14. 73-year-old woman & Low back pain, bilateral leg pain & Spondylosis, scoliosis & None diagnosed \\
\hline
\end{tabular}

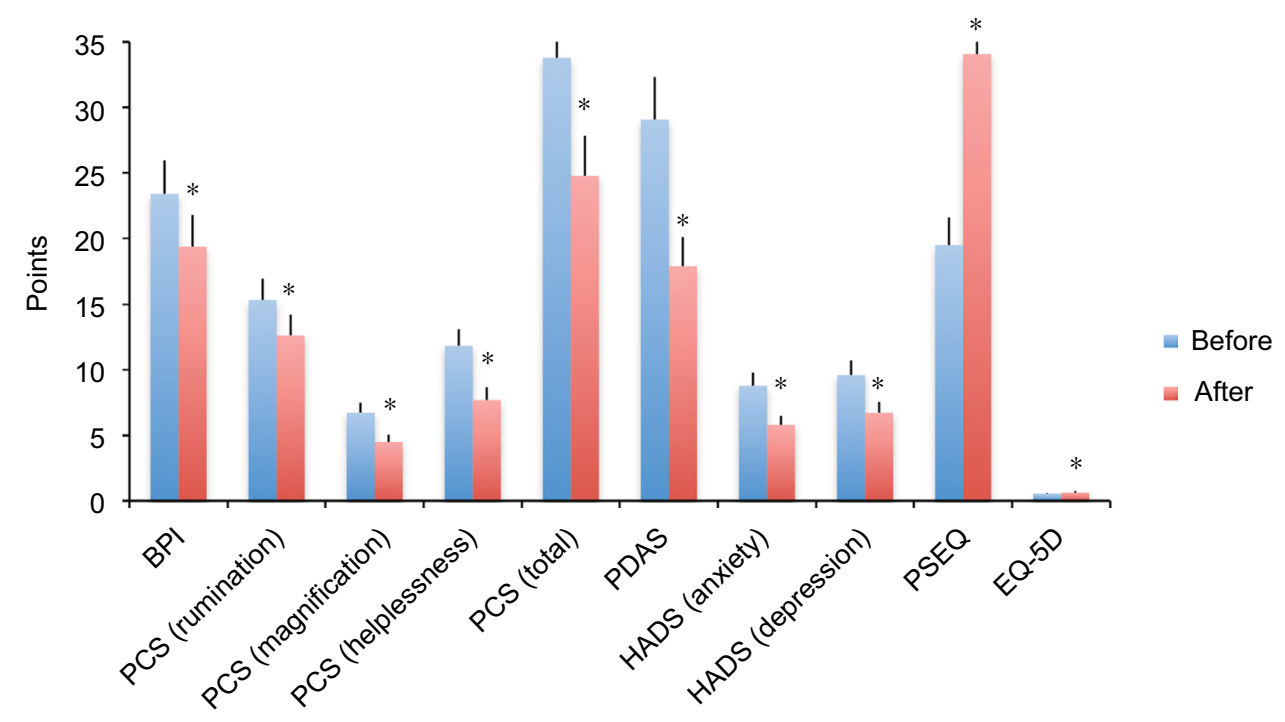

Figure I Changes of pain and associated factors.

Notes: ${ }^{*} p<0.05$.

Abbreviations: BPI, brief pain inventory; EQ-5D, EuroQol five dimensions questionnaire; HADS, hospital anxiety and depression scale; PCS, pain catastrophizing scale; PDAS, pain disability assessment scale; PSEQ, pain self-efficacy questionnaire.

Orthopedic surgeons of our team assessed the patient's physical, neurological, and imaging findings (lumbar radiographs/radiography and magnetic resonance imaging), and found no abnormal findings, no neurological deficits, and no abnormal structural disorders. He was diagnosed with nonspecific low back pain. The psychiatric diagnoses were 


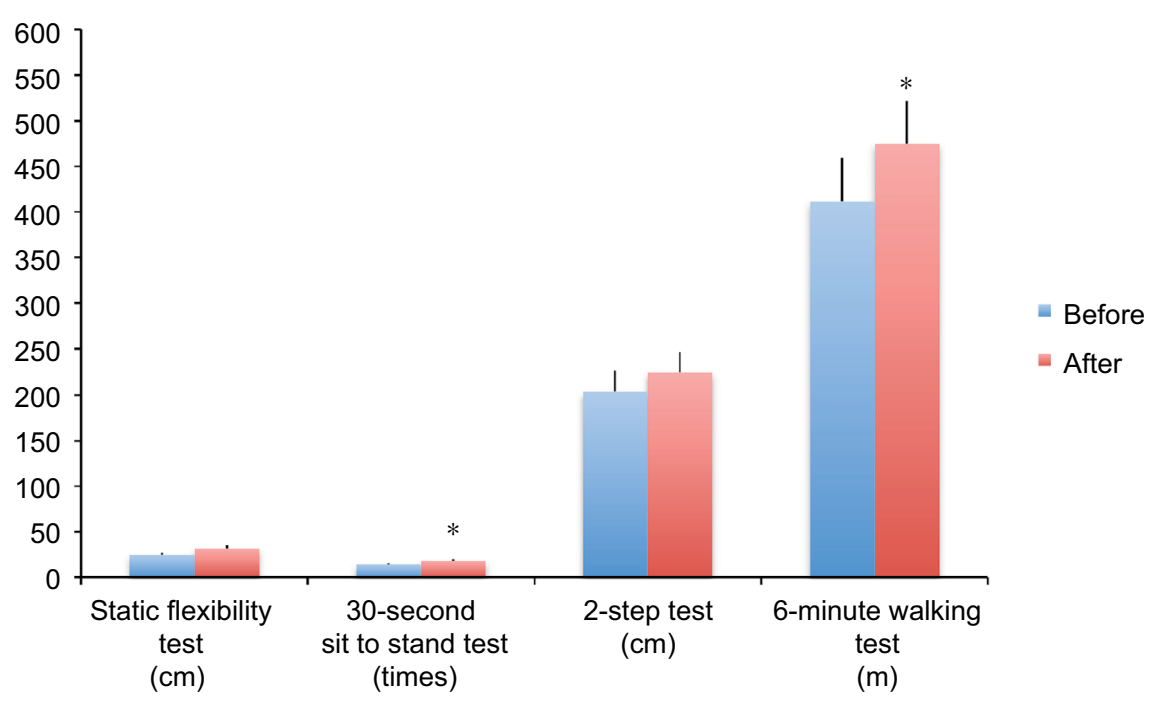

Figure 2 Changes in physical functions.

Note: ${ }^{*} p<0.05$.

Table 2 Changes of pain and associated factors

\begin{tabular}{llll}
\hline & $\begin{array}{l}\text { Before program } \\
\text { (Average } \pm \text { standard error) }\end{array}$ & $\begin{array}{l}\text { After program } \\
\text { (Average } \pm \text { standard error) }\end{array}$ & $p$-value \\
\hline BPI & $23.4 \pm 2.9$ & $19.4 \pm 2.3$ & 0.001 \\
PCS (rumination) & $15.3 \pm 1.0$ & $12.6 \pm 1.1$ & 0.01 \\
PCS (magnification) & $6.7 \pm 1.0$ & $4.5 \pm 0.8$ & 0.003 \\
PCS (helplessness) & $11.8 \pm 1.4$ & $7.7 \pm 0.9$ & 0.007 \\
PCS (total) & $33.8 \pm 3.1$ & $24.8 \pm 2.6$ & 0.003 \\
PDAS & $29.1 \pm 3.2$ & $17.9 \pm 3.1$ & 0.02 \\
HADS (anxiety) & $8.8 \pm 1.2$ & $5.8 \pm 1.0$ & 0.004 \\
HADS (depression) & $9.6 \pm 1.4$ & $6.7 \pm 1.3$ & 0.03 \\
PSEQ & $19.5 \pm 2.9$ & $34.1 \pm 3.1$ & 0.0002 \\
EQ-5D & $0.525 \pm 0.05$ & $0.643 \pm 0.04$ & 0.04 \\
\hline
\end{tabular}

Abbreviations: BPI, brief pain inventory; EQ-5D, EuroQol five dimensions questionnaire; HADS, hospital anxiety and depression scale; PCS, pain catastrophizing scale; PDAS, pain disability assessment scale; PSEQ, pain self-efficacy questionnaire.

Table 3 Changes of physical functions

\begin{tabular}{lllr}
\hline & $\begin{array}{l}\text { Before program } \\
\text { (Average } \pm \text { standard error) }\end{array}$ & $\begin{array}{l}\text { After program } \\
\text { (Average } \pm \text { standard error) }\end{array}$ & P-value \\
\hline Static flexibility test (flexibility) & $24.7 \pm 2.9 \mathrm{~cm}$ & $31.8 \pm 2.8 \mathrm{~cm}$ & 0.15 \\
30-second sit to stand test (muscle endurance) & $14.2 \pm 2.4 \mathrm{times}$ & $18.2 \pm 2.9 \mathrm{times}$ & 0.02 \\
2-step test (walking ability) & $203.2 \pm 15.0 \mathrm{~cm}$ & $224.5 \pm 12.3 \mathrm{~cm}$ & 0.15 \\
6 minutes walking test (physical fitness) & $411.7 \pm 40.7 \mathrm{~m}$ & $475.1 \pm 42.5 \mathrm{~m}$ & 0.03 \\
\hline
\end{tabular}

pervasive developmental disorder and ADHD (Table 1). We recommended that he enroll in the inpatient multidisciplinary pain management program at our hospital. He suffered severe pain, decreased QOL, mental anguish, and physical dysfunction. Psychiatric evaluations clarified that the stress was related to his work as a public servant and his relationship with his mother. The goals of therapy were to make him well enough to return to work and improve his relationship with his mother. Since he had difficulty remaining seated for extended periods, the goal of rehabilitation was to increase tolerance in the seated position. The rehabilitation plan included stretching to raise his level of flexibility and muscular endurance, and maintain a healthy posture. His ADHD was treated using selective noradrenalin reuptake inhibitors. Significant improvement was seen in pain severity, psychosocial factors, and QOL after 3 weeks of participation in the inpatient multidisciplinary pain management program compared with that before starting the program (Table 4). All the physical functions including flexibility, muscle endurance, walking ability, and physical fitness improved after the 
program as a result of the supervised exercise therapy by the physical therapists (Table 5). After discharge, he visited the pain management center as an outpatient once a week, the psychiatry clinic every 2 weeks, and the rehabilitation center or pool for underwater exercise once a week. He continued exercise every day. He also received counseling with regard to interpersonal relationships with a goal of returning to work. Finally, he returned to work as a public servant 7 months after completing the program.

\section{Discussion}

Our study of implementing a Japanese-style inpatient multidisciplinary pain management program was based on biopsychosocial models guided by the IASP recommendations. We showed that pain severity, pain-associated factors such as psychosocial factors, QOL, muscle endurance, and physical fitness in inpatients with intractable chronic musculoskeletal pain were statistically significantly improved after the program.

Table 4 Changes of the various scores after treatment in a representative patient

\begin{tabular}{lll}
\hline & Before treatment & 3W treatment \\
\hline $\begin{array}{l}\text { Degree of pain } \\
\text { BPI }\end{array}$ & 24 & 21 \\
Psychosocial factors & & \\
PCS (rumination) & 20 & 8 \\
PCS (magnification) & 16 & 10 \\
PCS (helplessness) & 9 & 3 \\
PDAS & 29 & 7 \\
HADS (anxiety) & 15 & 9 \\
HADS (depression) & 19 & 6 \\
PSEQ & 10 & 40 \\
QOL score & & \\
EQ-5D & 0.384 & 0.724 \\
\hline
\end{tabular}

Abbreviations: BPI, brief pain inventory; EQ-5D, EuroQol five dimensions questionnaire; HADS, hospital anxiety and depression scale; PCS, pain catastrophizing scale; PDAS, pain disability assessment scale; PSEQ, pain self-efficacy questionnaire; $3 \mathrm{~W}, 3$ weeks.

Table 5 Changes of physical function after treatment in a representative patient

\begin{tabular}{|c|c|c|}
\hline & $\begin{array}{l}\text { Before } \\
\text { treatment }\end{array}$ & $\begin{array}{l}3 \mathrm{~W} \\
\text { treatment }\end{array}$ \\
\hline \multicolumn{3}{|l|}{ Flexibility } \\
\hline Static flexibility test $(\mathrm{cm})$ & 22 & 36.5 \\
\hline \multicolumn{3}{|l|}{ Muscle endurance } \\
\hline 30 -second sit to stand test (times) & 10 & 15 \\
\hline \multicolumn{3}{|l|}{ Walking ability } \\
\hline 2-step test $(\mathrm{cm})$ & 246 & 295 \\
\hline \multicolumn{3}{|l|}{ Physical fitness } \\
\hline 6-minute walking test $(\mathrm{m})$ & 375 & 397 \\
\hline
\end{tabular}

Abbreviation: $3 \mathrm{~W}, 3$ weeks.

\section{A biopsychosocial model of well-being}

A biopsychosocial model ${ }^{2,3}$ of well-being is a very important concept in determining the underlying mechanisms in chronic musculoskeletal pain. This is a general model or approach incorporating the biological factors that constitute the physical structural disorders diagnosed by medical personnel, and the psychological and social factors that constitute stress, including a lack of control, depression, anxiety with regard to health and/or life issues, age, environment, and the patient's social situation. This model stresses the importance of using a psychological and social approach to treat pain that does not improve with pharmacotherapy and/or surgery. The IASP recommends an interdisciplinary or multidisciplinary pain management approach for treating chronic musculoskeletal pain. Interdisciplinary or multidisciplinary pain management approaches have been implemented in some institutes in Japan, but there remains no nationwide interdisciplinary or multidisciplinary pain management approach.

\section{Characteristics of our inpatient multidisciplinary pain management program}

The multidisciplinary pain management program in our hospital is an inpatient program. The characteristics of this program are that a team consisting of orthopedic surgeons, psychiatrists, nurses, physical therapists, clinical psychologists, pharmacists, and nutritionists treats patients with chronic musculoskeletal pain based on the patient's lifestyle and therapeutic targets, including sleep and nutrition, using cognitive behavioral therapy and exercise therapy. The goals of our program are as follows: 1) to decrease pain catastrophizing for chronic musculoskeletal pain, 2) to decrease pain behavior, and 3) to increase healthy behavior.

\section{Exercise therapy}

Exercise and stretching with pacing, including maintaining correct alignment and posture, training for trunk core muscle strength, and aerobic exercise such as walking, are important in treating chronic musculoskeletal pain. Exercise and stretching with pacing improves flexibility, muscle endurance, walking ability, and physical fitness, and also activates dopaminergic neurotransmission and/or serotonin and norepinephrine in descending spinal pain inhibition. ${ }^{16-20}$ The supervised exercise therapy, which includes aerobic exercise such as walking and underwater exercise, and stretching with pacing, has an important role in our inpatient pain management program. 


\section{Pathomechanisms of chronic musculoskeletal pain \\ Psychological factors related to chronic musculoskeletal pain}

Previous studies have suggested that 1) pain-related fear and avoidance appear to be essential features of the development of a chronic pain state in patients with musculoskeletal pain, ${ }^{21-29}$ and 2) fear-avoidance beliefs and catastrophizing have been implicated in chronic pain and may interact with the experience of pain. ${ }^{30,31}$ These studies suggest that it is very important to decrease fear-avoidance beliefs and pain catastrophizing to improve the QOL of patients with chronic musculoskeletal pain. The importance of psychological factors such as depression, anxiety, and catastrophizing in the development of pain severity and physical functioning has also been reported. ${ }^{32-34}$ We confirmed decreased pain behavior and increased healthy behavior in patients with chronic musculoskeletal pain after completing our program. Vachon-Presseau et al suggested that corticolimbic anatomical characteristics predetermine the risk for chronic pain, and a high prevalence of depression and negative affect are associated with risk for chronic pain..$^{35}$ Also, Jiang Y et al reported that 1) patients with chronic pain had exaggerated and abnormal amygdala connectivity with central executive network, which was most exaggerated in patients with the greatest pain catastrophizing, and 2) the normally basolateral-predominant amygdala connectivity to the default mode network was blunted in patients with chronic pain. ${ }^{36}$ Patients' fear-avoidance beliefs and catastrophizing may involve exaggerated and abnormal amygdala connectivity with the central executive network. Following our inpatient pain management program, our patients showed decreased fear-avoidance beliefs and catastrophizing, and improved pain levels and aggressive self-expression. The results of the current study support these findings.

Social factors related to chronic musculoskeletal pain Eisenberger et al suggested that the anterior cingulate cortex was more active during social exclusion than during social inclusion in a physical pain study, and that the right ventral prefrontal cortex was active during social exclusion and correlated negatively with self-reported distress in a neuroimaging study. ${ }^{37}$ The authors suggested that these findings might be very important during social inclusion; that the family or a significant other is necessary when treating patients with chronic musculoskeletal pain. Our inpatient pain management program includes family or significant others, since we believe that another person's support is essential.

\section{Multidisciplinary pain management programs for chronic musculoskeletal pain}

Scascighini et al opined that compared with other nondisciplinary treatments, moderate evidence of higher effectiveness for multidisciplinary interventions was shown. ${ }^{38}$ Other countries have also implemented multidisciplinary pain management programs ${ }^{39-55}$ For instance, the University of Washington Center for Pain Relief in Seattle, WA, USA, which was one of the first establishments for interdisciplinary and/or multidisciplinary pain management in the world, has outpatient programs that include treatment for acute and chronic pain using intervention therapy. ${ }^{45}$ Their multispecialty clinical team consists of internists, psychiatrists, anesthesiologists, physical therapists, pharmacists, and nurses. The center's treatment outcomes are very good and patient satisfaction is high. Similar programs in Japan include a multidisciplinary approach at Aichi Medical University $^{46}$ that involves a 9-week outpatient program based on cognitive behavioral therapy and exercise for patients with refractory chronic pain, and a multidisciplinary outpatient program at Okayama University for patients with intractable chronic pain. ${ }^{47}$ These teams consist of orthopedic surgeons, psychiatrists, anesthesiologists, nurses, physical therapists, trainer, and nutritionists at the Aichi Medical University, and orthopedic surgeons, anesthesiologists, psychiatrists, neurosurgeons, dental anesthesiologists, nurses, physical therapists, occupational therapists, clinical psychologists, and social workers at the Okayama University. Another program at Whittington Hospital, London, UK, ran 1 afternoon per week for 7 weeks and was conducted by a multidisciplinary team aiming to increase patients' skills for coping with chronic pain and its social, emotional, and physical consequences. ${ }^{48}$

The efficacy of an inpatient multidisciplinary pain management program has been reported in several studies. ${ }^{49-55}$ Our pain management program is an inpatient multidisciplinary program with a team consisting of orthopedic surgeons, psychiatrists, nurses, physical therapists, clinical psychologists, pharmacists, and nutritionists. We compared the outcomes of our inpatient multidisciplinary pain management program with those of other facilities. Table 6 shows the multidisciplinary pain management programs in other facilities. ${ }^{49-54} \mathrm{The}$ program at the Rehabilitation Medicine $\mathrm{Clinic}^{49}$ in cooperation with the University of Washington Center for Pain Relief includes a multidisciplinary rehabilitation team consisting of rehabilitation medicine physicians, pain psychologists, and physical and occupational therapists. Patients stay near the hospital for 4 weeks - 1 week longer than our inpatient program. Their treatment program is similar to ours, based on 
Table 6 Inpatient multidisciplinary pain management programs in other countries

\begin{tabular}{|c|c|c|c|c|}
\hline Facility & Staff & Hospitalization & Treatment method & Outcomes \\
\hline $\begin{array}{l}\text { Washington Center } \\
\text { for Pain Relief (Seattle, } \\
\text { WA, USA) }\end{array}$ & $\begin{array}{l}\text { Rehabilitation medicine } \\
\text { physicians, pain } \\
\text { psychologists, physical } \\
\text { and occupational } \\
\text { therapists, vocational } \\
\text { counselors }\end{array}$ & 4 weeks & $\begin{array}{l}\text { Multidisciplinary rehabilitation program, } \\
\text { which includes physical exercise and } \\
\text { reconditioning, and psychological } \\
\text { strategies for managing pain and the } \\
\text { associated emotional and behavioral } \\
\text { changes }\end{array}$ & $\begin{array}{l}\text { Improvements in reported } \\
\text { pain, pain worry, fear- } \\
\text { avoidance beliefs, depression, } \\
\text { and physical function, } \\
74 \% \text { of patients returned to } \\
\text { work or underwent retraining }\end{array}$ \\
\hline $\begin{array}{l}\text { Center for Clinical } \\
\text { Psychology and } \\
\text { Rehabilitation, } \\
\text { University of Bremen } \\
\text { (Bremen, Germany) }\end{array}$ & $\begin{array}{l}\text { Physicians, nurses, } \\
\text { therapists, clinical } \\
\text { psychologist }\end{array}$ & $3-4$ weeks & $\begin{array}{l}\text { Multidisciplinary inpatient orthopedic } \\
\text { rehabilitation program, which includes } \\
\text { physical exercise training, cognitive } \\
\text { behavioral therapy, progressive muscle } \\
\text { relaxation, and psychological counseling }\end{array}$ & $\begin{array}{l}\text { Significantly improved } \\
\text { psychological and pain-related } \\
\text { outcome measures, especially } \\
\text { anxiety level }\end{array}$ \\
\hline $\begin{array}{l}\text { Institute for } \\
\text { Physiotherapy, Bern } \\
\text { University Hospital } \\
\text { (Bern, Switzerland) }\end{array}$ & $\begin{array}{l}\text { Rheumatologists, } \\
\text { clinical psychologists, } \\
\text { physiotherapists, } \\
\text { occupational therapists, } \\
\text { nurses, a movement } \\
\text { analyst, and a humor } \\
\text { therapist }\end{array}$ & 4 weeks & $\begin{array}{l}\text { Interdisciplinary approach including } \\
\text { drug therapy, physiotherapy (aerobic } \\
\text { endurance training, qigong/tai chi } \\
\text { exercises), and individual psychotherapy } \\
\text { that includes cognitive behavioral therapy, } \\
\text { relaxation therapy, humor therapy, and } \\
\text { education in coping skills }\end{array}$ & $\begin{array}{l}\text { Significantly improved pain } \\
\text { scores, mental health, and } \\
\text { coping outcomes }\end{array}$ \\
\hline $\begin{array}{l}\text { University of } \\
\text { Duisburg-Essen (Essen, } \\
\text { Germany) }\end{array}$ & $\begin{array}{l}\text { Physicians, nurses, } \\
\text { mind-body therapists }\end{array}$ & 2 weeks & $\begin{array}{l}\text { Multidisciplinary pain management } \\
\text { program, which includes classical } \\
\text { naturopathy (hydrotherapy, } \\
\text { thermotherapy, manual therapy, massage, } \\
\text { physiotherapy, exercise, nutritional } \\
\text { therapy, and fasting), stress reduction, } \\
\text { nutritional counseling, and self-help skills }\end{array}$ & $\begin{array}{l}\text { Significant improvements in } \\
\text { pain intensity, pain disability, } \\
\text { pain perception, quality of life, } \\
\text { depression, and perceived } \\
\text { stress }\end{array}$ \\
\hline $\begin{array}{l}\text { Chronic Pain } \\
\text { Management and } \\
\text { Neuromodulation } \\
\text { Centre at St. Thomas's } \\
\text { Hospital (London, UK) }\end{array}$ & $\begin{array}{l}\text { Anesthesiologists, } \\
\text { clinical psychologists, } \\
\text { physical therapists, } \\
\text { occupational therapists, } \\
\text { and nurses }\end{array}$ & 4 weeks & $\begin{array}{l}\text { An inpatient cognitive behavioral pain } \\
\text { program with physical and psychological } \\
\text { assessment, exercise therapy and } \\
\text { stretching, and relaxation technique } \\
\text { training }\end{array}$ & $\begin{array}{l}\text { Significant improvements for all } \\
\text { measures of psychological and } \\
\text { physical function. } \\
\text { A majority of patients were } \\
\text { satisfied with the treatment }\end{array}$ \\
\hline $\begin{array}{l}\text { Auckland City Hospital } \\
\text { (Auckland, New } \\
\text { Zealand) }\end{array}$ & $\begin{array}{l}\text { Registered } \\
\text { psychiatrists, medical } \\
\text { and nursing staff, } \\
\text { psychologists, } \\
\text { physiotherapists, } \\
\text { occupational therapists, } \\
\text { and vocational } \\
\text { rehabilitation officers }\end{array}$ & 4 weeks & $\begin{array}{l}\text { Cognitive behavioral pain program, which } \\
\text { includes education about physiology } \\
\text { and psychology in pain; behavioral } \\
\text { pain management; promoting adaptive } \\
\text { cognitions via cognitive restructuring, } \\
\text { visualization, and imagery techniques; } \\
\text { exercise; individual, group, family, and } \\
\text { vocational counseling; medication; and } \\
\text { staff verbal reinforcement of patients' } \\
\text { activity }\end{array}$ & $\begin{array}{l}\text { Significant improvements at } \\
\text { posttreatment for measures } \\
\text { of psychological distress, } \\
\text { pain behavior, health-related } \\
\text { disability, and pain intensity } \\
\text { following physical exertion }\end{array}$ \\
\hline
\end{tabular}

multidisciplinary rehabilitation that includes pain education. The Washington program showed improvements in pain, pain worry, fear-avoidance beliefs, depression, and physical function. The program at the Center for Clinical Psychology and Rehabilitation at the University of Bremen in Germany ${ }^{50}$ is a multidisciplinary inpatient orthopedic rehabilitation program with a team of physicians, nurses, therapists, and clinical psychologist. Patients are hospitalized for 3-4 weeks. The Center also uses a multidisciplinary rehabilitation approach that includes pain education, and their outcome in psychological and pain-related outcome measures is similar to that of our program. The program at the Institute for Physiotherapy, Bern
University Hospital in Switzerland ${ }^{51}$ involves interdisciplinary inpatient therapy with a team of rheumatologists, clinical psychologists, physiotherapists, occupational therapists, nurses, a movement analyst, and a humor therapist. Patients are hospitalized for 4 weeks. Because their method involves interdisciplinary pain management, results may differ from our multidisciplinary program; however, the improvements in pain, mental health, and coping outcomes are similar to our results. The program at the University of Duisburg-Essen in Germany $^{52}$ is a multidisciplinary pain management program consisting of a team of physicians, nurses, and mind-body therapists. Patients are hospitalized for 2 weeks; treatment 
methods are similar to our multidisciplinary approach and include physiotherapy, exercise, stress reduction, and nutritional education. However, the program differs from ours because it also includes naturopathy. The improvements in pain intensity, pain perception depression, perceived stress, and QOL are similar to our results. The Chronic Pain Management and Neuromodulation Centre at St. Thomas's Hospital in London ${ }^{53}$ has a multidisciplinary pain management program consisting of a team of anesthesiologists, clinical psychologists, physical and occupational therapists, and nurses. Patients are hospitalized for 4 weeks, and the program involves a cognitive behavioral pain program with physical therapy, similar to our program, but differs in that they do not include nutritional education. The outcomes in all measures of psychological and physical function are similar to our program's results. The program at the Auckland City Hospital in Auckland, New Zealand, ${ }^{54}$ is a behavioral pain program involving a team of registered psychiatrists, medical and nursing staff, psychologists, physiotherapists, occupational therapists, and vocational rehabilitation officers, and the program includes education about the physiology and psychology of pain; behavioral pain management; promotion of adaptive cognitions via cognitive restructuring, visualization, and imagery techniques; exercise; individual group, family, and vocational counseling; medication; and verbal staff reinforcement of patients' activity. As in our program, the Auckland City Hospital's program involves educating both patients and family, and includes cognitive behavioral therapy and medications. The outcomes in measures of psychological distress, pain behavior, health-related disability, and pain intensity following physical exertion are similar to that of our results. Overall, the outcomes of our inpatient multidisciplinary pain management program are consistent with similar inpatient multidisciplinary pain management programs in other countries ${ }^{49-54}$ with regard to improved pain intensity, psychosocial factors such as fear-avoidance, physical function, and QOL. Hospitalization duration was 2-4 weeks in all the studies we used for comparison; ${ }^{49-54}$ therefore, our 3-week duration appears to be appropriate.

\section{Inpatient vs. outpatient pain management programs}

There are few randomized comparisons of inpatient vs. outpatient pain management programs. Scascighini et al found that the evidence that comprehensive inpatient programs were more beneficial than outpatient programs was moderate. ${ }^{38}$ Peters et al performed a randomized trial comparing inpatient and outpatient treatment and found improvement in both groups compared with untreated controls; however, inconsistent methodologies made direct comparisons of the 2 groups of patients impossible. ${ }^{54}$ The authors reported that at 1 year, inpatients showed a greater likelihood than outpatients of maintaining treatment gains, ${ }^{55}$ suggesting that inpatient programs were more useful for some patients with intractable chronic pain. Future studies comparing inpatient with outpatient pain management programs in detail would be useful.

\section{Limitations}

\section{Controversial points in our inpatient} multidisciplinary pain management program

Along with the advantages of our inpatient multidisciplinary pain management program, there are also weak and/or controversial points. First, although this program is open to all, we must consider each patient's rehabilitation, carefully. Second, because it may be difficult to sufficiently change the patients' cognition and behavior in a short period, it may be necessary to continue patient follow-up by each specialist after discharge. Finally, a high number of medical personnel are involved in this inpatient program, and incomes may not be adequately reflected because of the insufficient Japanese insurance system for chronic pain. We must correct these controversial points to generalize our inpatient program.

\section{Limitation in this study}

The present study has certain important limitations. First, there was no control group in this study. We compared the treatment outcomes of our inpatient multidisciplinary pain management program with previous programs in other countries; however, future studies, including a control group are required. Second, our study population was small; larger populations are needed in future studies. Third, the follow-up period was relatively short, and future studies are needed to evaluate long-term follow-up.

\section{Conclusion}

We developed an inpatient multidisciplinary pain management program and reported the results of our first 14 cases. Our inpatient multidisciplinary pain management program is being expanded to better help intractable chronic musculoskeletal pain patients.

\section{Acknowledgments}

The authors are very grateful to each participant in the study and the clinical staff who supported this research: Kou Matsudaira, Kozue Takatsuki, Hidemi Ohsuka, Saori 
Watanabe, Kana Hongo, Izumi Fujihashi, Yukie Moto, Mami Tanimoto, Kasumi Endo, Kenji Nihei, Minoru Iwasaki, Kazuaki Suzuki, Miho Ohuchi, Yoko Arase, Aki Kiryu, Yurika Nemoto, Yuta Yabuki, Yukiko Kokubun, and Shiori Kanno.

\section{Author contributions}

All authors made substantial contributions to conception and design, acquisition of data, or analysis and interpretation of data; took part in drafting the article or revising it critically for important intellectual content; gave final approval of the version to be published; and agreed to be accountable for all aspects of the work.

\section{Disclosure}

The authors report no conflicts of interest in this work.

\section{References}

1. Merskey H, Bogduk N; IASP Task Force on Taxonomy. Part III: Pain Terms, A Current List with Definitions and Notes on Usage Classification of Chronic Pain. 2nd ed. Seattle, WA: IASP Press; 1994: 209-214.

2. Turk DC, Monarch ES. Biopsychosocial perspective on chronic pain. In: Psychological Approaches to Pain Management: A Practitioner's Handbook. Turk DC, Gatchel RJ, editors. New York: Guilford; 2002.

3. Loeser JD. Conception of pain. In: Chronic Low Back Pain. StantonHicks M, Boas R. editors. New York: Raven Press; 1982:145-148.

4. Flor H, Turk DC. Chronic Pain: An Integrated Biobehavioral Approach. Seattle, WA: IASP Press; 2011.

5. Loeser JD, Butler SH, Chapman CR, Turk DC. Multidisciplinary pain management. In: Bonica's Management of Pain. Loeser JD et al., editors. Philadelphia, PA: Lippincott Williams \& Wilkins; 2001.

6. Turk DC, Okifuji A. Multidisciplinary pain management. In: Bonica's Management of Pain. Loeser JD et al., editors. Philadelphia, PA: Lippincott Williams \& Wilkins; 2001.

7. Kamper SJ, Apeldoorn AT, Chiarotto A, et al. Multidisciplinary biopsychosocial rehabilitation for chronic low back pain: cochrane systematic review and meta-analysis. BMJ. 2015;350:h444.

8. Otis JD, Reid MC, Kerns RD. The management of chronic pain in the primary care setting. In: Primary Care Clinical Health Psychology: A Model for the Next Frontier. James LC, Folen RA, editors. Washington, DC: American Psychological Association Press; 2005.

9. Melzack R, Wall PD. Pain mechanisms: a new theory. Science. 1965;150(3699):971-9795.

10. Ceeland CS, RyanKM. Pain assessment: global use of brief pain inventory. Ann Acad Med Singapore. 1994;23(2):129-138.

11. Osman A, Barrios FX, Gutierrez PM, Kopper BA, Merrifield T, Grittmann $\mathrm{L}$. The pain catastrophizing scale: further psychometric evaluation with adult samples. J Behav Med. 2000;23(4):351-365.

12. Yamashiro K, Arimura T, Iwaki R, Jensen MP, Kubo C, Hosoi M. A multidimensional measure of pain interference: reliability and validity of the pain disability assessment scale. Clin J Pain. 2011;27(4):38-343.

13. Zigmond AS, Snaith RP. The hospital anxiety and depression scale. Acta Psychiatr Scand. 1983;67(6):361-370.

14. Nicholas MK. The pain self-efficacy questionnaire: taking pain into account. Eur J Pain. 2007;11(2):153-163.

15. EuroQOL Group. EuroQol - a new facility for the measurement of health-related quality of life. Health Policy. 1990;16(3):199-208.

16. Wood PB. Role of central dopamine in pain and analgesia. Expert Rev Neurother. 2008;8(5):781-797.
17. Finan PH, Smith MT. The comorbidity of insomnia, chronic pain, and depression: dopamine as a putative mechanism. Sleep Med Rev. 2013;17(3):173-183.

18. Ossipov MH, Morimura K, Porreca F. Descending pain modulation and chronification of pain. Curr Opin Support Care. 2014;8(2):143-151.

19. Zheng X, Hasegawa H. Central dopaminergic neurotransmission plays an important role in thermoregulation and performance during endurance exercise. Eur J Sport Sci. 2016;16(7):818-828.

20. Cordeiro LMS, Rabelo PCR, Moraes MM, et al. Physical exerciseinduced fatigue: the role of serotonergic and dopaminergic systems. Braz J Med Biol Res. 2017;50(12):e6432.

21. Lethem J, Slade PD, Troup JD, Bentley G. Outline of a fearavoidance model of exaggerated pain perception-I. Behav Res Ther. 1983;21(4):401-408.

22. Slade PD, Troup JD, Lethem J, Bentley G. The fear-avoidance model of exaggerated pain perception-II. Behav Res Ther. 1983;21(4):409-416.

23. Vlaeyen JW, Linton SJ. Fear-avoidance and its consequences in chronic musculoskeletal pain: a state of the art. Pain. 2000;85(3):317-332.

24. Asmundson GJ, Noel M, Petter M, Parkerson HA. Pediatric fearavoidance model of chronic pain: foundation, application and future directions. Pain Res Manag. 2012;17(6):397-405.

25. Zale EL, Lange KL, Fields SA, Ditre JW. The relation between painrelated fear and disability: a meta-analysis. J Pain. 2013;14(10): 1019-1030.

26. Wideman TH, Asmundson GG, Smeets RJ, et al. Rethinking the fear avoidance model: toward a multidimensional framework of pain-related disability. Pain. 2013;154(11):2262-2265.

27. Edwards RR, Dworkin RH, Sullivan MD, Turk DC, Wasan AD. The role of psychosocial processes in the development and maintenance of chronic pain. J Pain. 2016;17(9):T70-T92.

28. Malfliet A, Coppieters I, Van Wilgen P, et al. Brain changes associated with cognitive and emotional factors in chronic pain: a systematic review. Eur J Pain. 2017;21(5):769-786.

29. Harvie DS, Moseley GL, Hillier SL, Meulders A. Classical conditioning differences associated_with chronic pain: a systematic review. $J$ Pain. 2017;18(8):889-898.

30. Linton SJ, Buer N, Vlaeyen J, Hellsing AL. Are fear-avoidance beliefs related to the inception of an episode of back pain? A prospective study, Psychol Health. 2000;14(6):1051-1059.

31. Matsudaira K, Kikuchi N, Murakami A, Isomura T. Psychometric properties of the Japanese version of the fear-avoidance beliefs questionnaire (FABQ). J Orthop Sci. 2014;19(1):26-32.

32. Teh CF, Zaslavsky AM, Reynolds CF 3rd, Cleary PD. Effect of depression treatment on chronic pain outcomes. Psychosome Med. 2010;71(1):61-67.

33. Angst F, Brioschi R, Main CJ, Lehmann S, Aeschlimann A. Interdisciplinary rehabilitation in fibromyalgia and chronic back pain: a prospective outcome study. J Pain. 2006;7(11):807-815.

34. Angst F, Verra ML, Lehmann S, Aeschlimann A, Angst J. Refined insights into the pain-depression association in chronic pain patients. Clin J Pain. 2008;24(9):808-816.

35. Vachon-Presseau E, Tétreault P, Petre B, et al. Corticolimbic anatomical characteristics predetermine risk for chronic pain. Brain. 2016;139(7):1958-1970.

36. Jiang Y, Oathes D, Hush J, et al. Perturbed connectivity of the amygdala and its subregions with the central executive and default mode networks in chronic pain. Pain. 2016;157(9):1970-1978.

37. Eisenberger NI, Lieberman MD, Williams KD. Does rejection hurt? An FMRI study of social exclusion. Science. 2003;10(302):290-292.

38. Scascighini L, Toma V, Dober-Spielmann S, Sprott H. Multidisciplinary treatment for chronic pain: a systematic review of interventions and outcomes. Rheumatology. 2008;47(5):670-678.

39. Tan SY. Cognitive and cognitive-behavioral methods for pain control: a selective review. Pain. 1982;12(3):201-228.

40. Aronoff GM, Evans WO, Enders PL. A review of follow-up studies of multidisciplinary pain units. Pain. 1983;16(1):1-11. 
41. Linton SJ. Behavioral remediation of chronic pain: a status report. Pain. 1986;24(2):125-141.

42. Philips HC. The effects of behavioural treatment on chronic pain. Behav Res Ther. 1987;25(5):365-377.

43. Malone MD, Strube MJ, Scogin FR. Meta-analysis of non-medical treatments for chronic pain. Pain. 1988;34(3):231-244.

44. Kamper SJ, Apeldoorn AT, Chiarotto A, et al. Multidisciplinary biopsychosocial rehabilitation for chronic low back pain. Cochrane Database Sys Rev. 2014;9:CD000963.

45. Dale R, Stacey B. Multimodal treatment of chronic pain. Med Clin North Am. 2016;100(1):55-64.

46. Inoue $\mathrm{M}$, Inoue $\mathrm{S}$, Ikemoto $\mathrm{T}$, et al. The efficacy of a multidisciplinary group for patients with refractory chronic pain. Pain Res Manag. 2014;19(6,):302-308.

47. Tetsunaga T, Tetsunaga T, Nishie H. Establishment of a liaison clinic for patients with intractable chronic pain. J Orthop Sci. 2015;20(5):907-913.

48. Skinner JB, Erskine A, Pearce S. The evaluation of a cognitive behavioural treatment programme in outpatients with chronic pain. $J$ Psychosom Res. 1990;34(1):13-19.

49. Kroll HR. Exercise therapy for chronic pain. Phys Med Rehabili Clin NAm. 2015;26(2):263-281.
50. Hampel P, Graef T, Krohn-Grimberghe B, Tlach L. Effects of gender and cognitive-behavioral management of depressive symptoms on rehabilitation outcomes among inpatient orthopedic patients with chronic low back pain: a 1 year longitudinal study. Eur Spine J. 2009;18(12):1867-1880.

51. Verra ML, Angst F, Staal JB, et al. Differences in pain, function and coping in multidimensional pain inventory subgroups of chronic back pain: a one-group pretest-posttest study. BMC Musculoskelet Disord. 2011;12(145): 10 .

52. Saha FX, Brüning A, Barcelona $C$, et al. Integrative medicine for chronic pain: a cohort study using a process-outcome design in the context of a department for internal and integrative medicine. Medicine (Baltimore). 2016;95(27):e4152.

53. Williams AC, Nicholas PH, Richardson PH, et al. Evaluation of a cognitive behavioural programe for rehabilitating patients with chronic pain. Br J Gen Pract. 1993;43(377):513-518.

54. Peters JL, Large RG. A randomized control trials evaluating in- and out-patient pain management programmes. Pain. 1990;41(3):283-293.

55. De C Williams AC, Nicholas MK, Richardson PH, Pither CE, Fernandes J. Generalizing from a controlled trial: the effects of patient preference versus randomization on the outcome of inpatient versus outpatient chronic pain management. Pain. 1999;83(1):57-65.
Journal of Pain Research

\section{Publish your work in this journal}

The Journal of Pain Research is an international, peer reviewed, open access, online journal that welcomes laboratory and clinical findings in the fields of pain research and the prevention and management of pain. Original research, reviews, symposium reports, hypothesis formation and commentaries are all considered for publication.

\section{Dovepress}

The manuscript management system is completely online and includes a very quick and fair peer-review system, which is all easy to use. Visit http://www.dovepress.com/testimonials.php to read real quotes from published authors. 